\title{
Neural correlates of saccadic inhibition in healthy elderly and patients with amnestic mild cognitive impairment
}

\author{
K. K. Alichniewicz' ${ }^{1}$, F. Brunner ${ }^{1}$, H. H. Klünemann ${ }^{2}$ and M. W. Greenlee ${ }^{1 *}$ \\ 1 Institute of Experimental Psychology, University of Regensburg, Regensburg, Germany \\ ${ }^{2}$ Departments of Psychiatry, Psychosomatics, and Psychotherapy, University of Regensburg, Regensburg, Germany
}

\author{
Edited by: \\ Allison B. Sekuler, McMaster \\ University, Canada \\ Reviewed by: \\ Joseph F.X. DeSouza, York \\ University, Canada \\ Frans W. Cornelissen, University \\ Medical Center Groningen \\ Netherlands \\ *Correspondence: \\ M. W. Greenlee, Institute of \\ Experimental Psychology, University \\ of Regensburg, Universitätsstraße \\ 31, 93053 Regensburg, Germany \\ e-mail:mark.greenlee@ \\ psychologie.uni-regensburg.de
}

Performance on tasks that require saccadic inhibition declines with age and altered inhibitory functioning has also been reported in patients with Alzheimer's disease. Although mild cognitive impairment (MCl) is assumed to be a high-risk factor for conversion to $A D$, little is known about changes in saccadic inhibition and its neural correlates in this condition. Our study determined whether the neural activation associated with saccadic inhibition is altered in persons with amnestic mild cognitive impairment (aMCl). Functional magnetic resonance imaging (fMRI) revealed decreased activation in parietal lobe in healthy elderly persons compared to young persons and decreased activation in frontal eye fields in aMCl patients compared to healthy elderly persons during the execution of anti-saccades. These results illustrate that the decline in inhibitory functions is associated with impaired frontal activation in $\mathrm{aMCl}$. This alteration in function might reflect early manifestations of $A D$ and provide new insights in the neural activation changes that occur in pathological ageing.

Keywords: mild cognitive impairment, Alzheimer's disease (AD), ageing, inhibition functions, anti-saccades, fMRI

\section{INTRODUCTION}

Ageing is associated with a decline in cognitive functioning along with structural and functional changes in the brain. A large body of behavioral research on the effect of ageing on human cognition has found that age-related deteriorations are observed across a range of cognitive domains including processing speed, working memory and inhibition (Moscovitch and Winocur, 1992; Braver and Barch, 2002; Anderson et al., 2012; Heilbronner and Münte, 2013). The process of ageing, however, does not inevitably lead to cognitive decline and the extent of the cognitive decline varies in different individuals across various tasks (Rapp and Amaral, 1992; McDowd, 1997; Friedman et al., 2008; Park and ReuterLorenz, 2009). Thus, more research is required to understand neurocognitive changes related to human ageing. A major challenge for ageing researchers is to acquire a better distinction between normal and pathological changes with age.

A transitional state between normal and pathologic ageing that is associated with an increased risk of progression to $\mathrm{AD}$ is defined as mild cognitive impairment (MCI) (Petersen, 2004). Based on the results of numerous studies on pathological ageing, it is clear that there is no single framework that describes the neuropathology of MCI (Stephan et al., 2012a,b). The complexity and heterogeneity of this condition is reflected in the considerable variability in the definition, characterization and application of the MCI diagnosis in the clinical practice (for the review see: Stephan et al., 2012a). It is widely accepted, however, that there are many subtypes of MCI. According to Petersen (2004), amnestic (aMCI) or non-amnestic MCI (naMCI) should be differentiated from each other. This classification depends on whether memory decline is exhibited in MCI patients. Individuals with intact memory abilities are diagnosed with naMCI as opposed to the individuals with memory impairment diagnosed as aMCI (Petersen, 2003, 2007). It has been suggested that the various MCI subtypes have different etiologies and outcomes (Sachdev et al., 2012). Therefore, individuals diagnosed with aMCI are thought to be more likely to progress to AD (Hunderfund et al., 2006; Petersen and Jack, 2009). In addition to episodic and semantic memory deficits in aMCI patients (Fox et al., 1998; Petersen, 2004; Chertkow et al., 2008), several recent studies suggest that deterioration of executive functions is associated with the conversion to AD (Greenwood, 2000; Rozzini et al., 2007; Iachini et al., 2009; Alichniewicz et al., 2012). Furthermore, there is some evidence that individuals demonstrate deficits in executive functions 2-3 years before diagnosis of AD (Johnson et al., 2009).

Studies on changes in cognition with age showed that while excitatory aspects of attention (like directed visual attention) are preserved in elderly persons, inhibitory processes decline with age (Hasher and Zacks, 1988; Sweeney et al., 2001; Crawford et al., 2005; Peltsch et al., 2011). Age-related inhibitory impairment, however, is restricted to specific inhibitory functions associated with prepotent response inhibition (Butler et al., 1999; Friedman and Miyake, 2004; Mirsky et al., 2011). According to Friedman and Miyake (2004), inhibition of prepotent responses is an ability to deliberately suppress an automatic and dominant action or to ignore no longer relevant contents when necessary. The inhibition of prepotent responses reveals resistance to preseverate and to exhibit controlled and intended reaction (Miyake et al., 2000). As postulated by Miyake et al. (2000), the tasks used to assess this function are the Stroop task (Stroop, 1935), the antisaccade task (Hallett, 1978), and the stop-signal task (Logan, 1994) as 
they all require the participants to intentionally stop an automatic response. Recent studies showed that performance on oculomotor tasks declines with age (Sweeney et al., 2001; Raemaekers et al., 2006; Peltsch et al., 2011). Elderly adults demonstrate reduced ability to voluntary inhibit saccadic response, as assessed by antisaccade tasks, and exhibit significantly increased onset latencies of correct anti-saccades compared to young adults (Olincy et al., 1997; Butler et al., 1999; Nieuwenhuis et al., 2000; Crawford et al., 2005; Peltsch et al., 2011). In contrast, their performance on automatic saccadic initiation, as assessed by reflexive prosaccadic tasks, does not deteriorate in healthy ageing. Older adults, however, need significantly more time to generate prosaccades accurately (Sweeney et al., 2001; Peltsch et al., 2011).

Altered inhibitory functioning has also been reported in dementia of Alzheimer's type (Currie et al., 1991; Crawford et al., 2005; Mosimann et al., 2005). In a review, Amieva et al. (2004) suggests that the deterioration of inhibitory functions in Alzheimer's disease (AD) may not be a general deficit. In particular, patients with $\mathrm{AD}$ demonstrated impairments on tasks requiring controlled inhibitory processes, such as the Stroop task (Fisher et al., 1990; Amieva et al., 2002; Belleville et al., 2006) and the anti-saccade task (Fletcher and Sharpe, 1986; Kaufman et al., 2010, 2012), whilst there is no effect of AD on the performance on tasks requiring more automatic inhibition, such as inhibition of return (Langley and Madden, 2000). The inability of persons with $\mathrm{AD}$ to perform anti-saccades may be associated with substantial neural degeneration in the frontal cortex (Fletcher and Sharpe, 1986; Crawford et al., 2005; Kaufman et al., 2010). Furthermore, the literature shows that the anti-saccade task can also be used to distinguish between different types of dementia and other forms of degenerative disorders (Boxer et al., 2006; Garbutt et al., 2008; Lagun et al., 2011).

Despite the fact that there is clear evidence for inhibition deficits in $\mathrm{AD}$, the extent of the deterioration of inhibition has rarely been studied in patients with MCI. Furthermore, there is some inconsistency in the literature with respect to the role of response inhibition in this disorder. While some authors point out that patients with aMCI demonstrate an impairment of inhibitory functions, as assessed by Stroop task (Kramer et al., 2006; Traykov et al., 2007; Bélanger et al., 2010), others argue that MCI has no effect on the performance on this task (Zhang et al., 2007). Moreover, patients with MCI show deterioration of the semantic inhibition of a prepotent response and impairment of inhibition functions may have predictive value with regard to a probable disease progression to $\mathrm{AD}$ (Bélanger and Belleville, 2009). On the neural level, increased activity in the dorsal anterior cingulate, bilateral middle and inferior frontal gyri, bilateral inferior parietal lobule, and the bilateral insula was evident in relation to the Stroop task reported in patients with MCI compared to young persons (Li et al., 2009). Crutcher et al. (2009) demonstrated that an oculomotor version of the visual paired-comparison task can be used for assessing normal and impaired recognition memory. Furthermore, Lagun et al. (2011) suggest that machine-learning techniques using the results of a visual paired-comparison task can be used to distinguish MCI from cognitive intact elderly persons. Therefore, there is some suggestions that eye movement functions are impaired in MCI.
To our knowledge, there is no study investigating the neural correlates of oculomotor functions in aMCI. The ability to voluntarily suppress an automatic response in favor of performing an alternative behavior is considered to be one of the crucial executive functions required in everyday life (Munoz and Everling, 2004). Since deterioration of this ability has been found in AD, we hypothesized that neural activation associated with oculomotor performance in anti-saccade tasks should be reduced in persons with aMCI, whereas neural activation for pro-saccades should be unaffected. Specifically, we hypothesize that patients with amnestic MCI will exhibit more errors on the anti-saccade task, while demonstrating reduced activation in saccade-controlling regions in prefrontal and parietal cortex.

\section{METHODS \\ PARTICIPANTS}

In order to investigate the effects of normal and pathological ageing on cognition and brain activation, three subject groups were assessed: aMCI patients $[n=23$, mean age $=60.3(9.3)$ years $]$, healthy elderly controls $[n=19$, mean age $=58.8$ (7.4) years] and healthy young persons $[n=13$, mean age $=24.6$ (2.1) years $]$. Participants with MCI were recruited from the Memory Clinic of the Department of Psychiatry, Psychosomatics and Psychotherapy of the University of Regensburg or via advertising in print media seeking healthy adults over 50 years of age who would like to participate in an fMRI-study. In order to exclude possible presence of any other neurological, psychiatric, or systemic condition among both groups, which may lead to alterations in cognitive status, subjects underwent a two-stage screening process to identify those with probable MCI. The first stage consisted of a structured telephone interview assessing evidence of subjective and informant-corroborated reports of memory problems and the presence of any exclusion criteria, including: history of significant medical, neurological, or psychiatric condition, history of major risk factors for vascular disease, history of alcohol and nicotine abuse or sensory impairment (visual acuity), use of psychoactive medication and any aspect that would disqualify a person to enter the MRI scanner (e.g., cardiac pacemaker). The second stage of the screening procedure involved a standardized diagnostic assessment of the cognitive, neuropsychological, and psychological state of the participants. The healthy control group consisted of adults that were recruited from the community via the same ad in the local media. Healthy elderly adults underwent the same clinical and neuropsychological procedure as aMCI patients to ensure that they did not demonstrate any cognitive complaints and did not have any medical history of significance. Finally, young participants were recruited from the community and via word-of-mouth communication. They were examined in the same way as the other two groups of participants, with the exclusion of the test batteries for clinical diagnosis of MCI.

Persons with MCI met the revised criteria for amnestic MCI as proposed by Artero et al. (2006) that included: evidence of decline in memory and other cognitive functions that is, however, insufficient to meet the Diagnostic and Statistical Manual for Mental Disorders-Fourth Edition (DSM-IV) criteria for dementia of the Alzheimer type (American Psychiatric Association, 1994). 
Neuropsychological assessment consisted of neuropsychological test battery contained in the Consortium to Establish a Registry for Alzheimer's Disease (CERAD+, German version; Memory Clinic Basel, 2005). The critical range of the CERAD was a z-score below -1.5 standard deviations (SD) but not less than $-3 \mathrm{SD}$ in at least one CERAD memory subtest for the MCI group and $z$ scores of at least above $-1.5 \mathrm{SD}$ in all CERAD subtests for the healthy control subjects. Memory subtests in CERAD+ critical for the diagnosis included: Wordlist Delayed Recall and Savings, TMT-A, Recall of Constructional Praxis, Constructional Praxis: Savings (see Table 1).

All participants were able to understand, and follow verbal instructions, and concentrate on the task for the duration of the experiment. They all were right-handed (according to the Handedness Inventory of Raczkowski et al., 1974), and had normal or corrected-to-normal vision using their own contact lenses or MR-safe refractive corrections provided by us.

\section{STUDY DESIGN}

\section{Procedure}

The procedures used in this study were approved by the Ethical Committee of the University of Regensburg. In accordance with the requirements of the Code of Ethical Principles for Medical Research Involving Human Subjects of the World Medical Association (Declaration of Helsinki), all participants provided written informed consent prior to the commencement of the study.

\section{Pro-saccade and anti-saccade task}

In order to investigate the effect of normal and pathological ageing on prepotent inhibition, the pro- and anti-saccades paradigm was employed. During each trial, a fixation cross $\left(0^{\circ}\right)$ appeared in the center of the computer display for a variable amount of time 5000, 5100, or $5200 \mathrm{~ms}$ (durations jittered with $100 \mathrm{~ms}$ increments). A target stimulus was presented on one of four different peripheral positions along the horizontal midline $\left( \pm 5\right.$ and $\left.15^{\circ}\right)$ for $200 \mathrm{~ms}$. The location of the target was randomized and counterbalanced so that participants were unable to predict at which position the target would be presented next. The saccade target was presented at one of the possible locations for $200 \mathrm{~ms}$. Then, a visual feedback appeared at the eccentric location of the pro-saccade target or anti-saccade location (a tiny green dot), visible only when the fovea was near the target location. The distractor locations were baited with a tiny red dot. On error trials, the red dot was visible to the participant, signaling that they executed a saccade to the wrong location. After this, the feedback dot was extinguished to be replaced immediately with the centrally located fixation dot, inducing a recentering saccade. Feedback was given on all trials in both training and fMRI sessions. After $1800 \mathrm{~ms}$ of central fixation, another trial began. Each task was performed 8 times during 5 blocks for pro- and

Table 1 | Description of demographic data and results of neuropsychological testing in amnestic mild cognitive impairment (aMcl) and healthy age-matched control groups.

\begin{tabular}{|c|c|c|c|c|}
\hline Parameters & Healthy elderly & aMCl & $T(d f=40)$ & $p$ \\
\hline \multicolumn{5}{|l|}{ DEMOGRAPHY } \\
\hline$N$ & 19 & 23 & & \\
\hline Gender (M/F) & $8 / 11$ & $5 / 18$ & 2.02 & 0.192 \\
\hline Education (years) & $14.74(2.26)$ & $13.09(3.26)$ & -1.87 & 0.069 \\
\hline Verbal fluency & $29.53(6.15)$ & $22.61(5.70)$ & -3.78 & 0.001 \\
\hline Boston naming test & $14.74(0.45)$ & $14.04(1.11)$ & -2.74 & 0.010 \\
\hline Word list learning & $22.58(2.78)$ & $18.70(2.99)$ & -4.33 & 0.000 \\
\hline Word list recall & $8.79(1.08)$ & $5.87(1.71)$ & -6.43 & 0.000 \\
\hline Word list: savings & $0.97(0.09)$ & $0.78(0.22)$ & -3.75 & 0.001 \\
\hline TMT-B & $69.33(26.42)$ & $84.83(35.43)$ & 1.55 & 0.130 \\
\hline Constructional praxis & $10.95(0.23)$ & $10.74(0.69)$ & -1.36 & 0.184 \\
\hline Recall of constructional praxis & $10.58(0.84)$ & $8.48(1.93)$ & -4.72 & 0.000 \\
\hline Constructional praxis: savings & $0.96(0.06)$ & $0.79(0.17)$ & -4.50 & 0.000 \\
\hline
\end{tabular}

Statistical tests of possible group differences (T-values and p-values) are presented.

aMCl, amnestic mild cognitive impairment; denoted are mean values, standard deviations (in brackets), $T$-, degrees of freedom (df) and p-values.

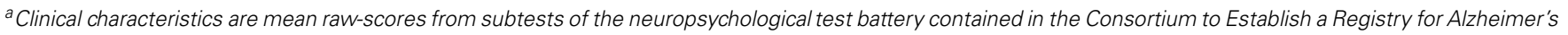
Disease Plus (CERAD-Plus).

Significant values $(p<0.05)$ are marked in bold font. 
anti-saccade tasks each, with a total number of 80 trials. On pro-saccade trials the central fixation dot turned green $500 \mathrm{~ms}$ prior to fixation offset, while on anti-saccade trials it turned red (see e.g., Connolly et al., 2002; Cornelissen et al., 2002). Also, a visual instruction ("look toward the target" vs. "look away from the target" ("Hinschauen" and "Wegschauen" in German, respectively) was presented for $5000 \mathrm{~ms}$ before each block of trials in each task. Participants were instructed to look toward the peripheral target as fast as they could during the "green" trials and to look as fast as possible to the mirror image location of the peripheral target during the "red" trials. During fixation epochs, participants were asked to keep their eyes on the central target. Approximately one week before the fMRI scan, all participants performed a pro-saccade and anti-saccade training experiment. We acquired 40 trials of pro-saccades and 40 trials of anti-saccades, in a similar blocked fashion as to be applied in the scanner, using the video eyetracker. Additionally, all participants were shown 8 trials of each task prior to the fMRI scan on the day of examination to refresh their memory on the task specifics. Feedback was also presented during these training trials.

\section{Stimulus presentation and eye-tracking}

For stimuli presentation we used Presentation 9.9 (Neurobehavioral Systems Inc., Albany, California, USA) on a standard PC, equipped with a standard graphics card and back projected via an LCD video projector (JVC, DLA-G20, Yokohama, Japan) onto a translucent circular screen (approximately 30 degrees visual angle in diameter), placed inside the scanner bore at $62 \mathrm{~cm}$ from the observer. The projector was running at $72 \mathrm{~Hz}$ with a resolution of $800 \times 600$ and a color resolution of $3 \times 8$ bit $(\mathrm{RBG})$. During training outside the MR-scanner we used High Speed Video Eye-Tracker Toolbox ${ }^{\mathrm{TM}}$ (Cambridge, http://www.crsltd.com/catalog/eyetracker-250/ index.html), where the participant was seated upright with their chin resting on a chinrest. During the fMRI scan, subjects viewed the stimuli through a mirror located above their eyes. Eye movements were recorded using the MR-Eyetracker (Cambridge Research Systems, Ltd), a fiberoptic limbus-tracking device positioned on the headcoil to monitor task performance. Owing to problems related to signal-to-noise in the eye-tracking data collected in the scanner, we were only able to verify task compliance "on-line" and could not conduct a off-line analysis of the eye-movement data. The results reported in Table 3 (see below) were collected during the training period outside of the scanner using the video eyetracker.

\section{Magnetic resonance imaging}

Functional magnetic resonance imaging (fMRI) was conducted on a 3-Tesla head scanner (Siemens Allegra, Erlangen, Germany). A localizer scan for placing the volume of interest was first acquired. In order to obtain a 3D anatomical model of the brain scan, high-resolution, sagittal T1-weighted images were acquired by using a magnetization-prepared gradient echo (MP-RAGE) sequence. The anatomical data set consisted of 160 sagittal slices, FoV $256 \mathrm{~mm}$, slice thickness $1.00 \mathrm{~mm}$, TR $2250 \mathrm{~ms}$, TE $2.6 \mathrm{~ms}$, flip angle $90^{\circ}$. For functional analysis a total of 610 functional volumes were acquired.
Each functional scan contained 34 3-mm slices, positioned oblique to the axial plane using a $\mathrm{T} 2 *$-weighted EPI sequence $\left(T R=2.0 \mathrm{~s}, T E=30 \mathrm{~ms}, 3 \times 3 \times 3 \mathrm{~mm}^{3}\right.$ voxel size, flip angle $\left.90^{\circ}\right)$.

\section{DATA ANALYSIS}

The evaluation of the eye movements was conducted manually using Matlab. Owing to the limitations on the signal-to-noise of the in-scanner eyetracking data, we base our analysis of the behavioral data on the video eyetracking data acquired during the training session outside of the scanner. We analyzed the eye trajectories offline and evaluated the task performance of the subjects. For both tasks, hit rates of the correct eye movements and reaction times were calculated. Accuracy rates among the groups exceeded chance performance in every group. A saccadic response was considered correct when the eye-movement direction was correct and the saccade landing point was near $\left( \pm 2^{\circ}\right)$ the peripheral visual target location. Reflexive pro-saccades that were not executed toward the mirror image location of the peripheral target were classified as errors in the anti-saccade task. Saccadic reaction time was calculated as the time from stimulus onset to saccadic onset. In the anti-saccade task, only data from trials where the saccades directed gaze toward the mirror location of the visual stimulus were scored as correct. For both conditions, saccades with reaction time less than $100 \mathrm{~ms}$ were classified as anticipatory and thus excluded from further analysis ( $0.5 \%$ of all saccades). The groups did not differ with respect to frequency of anticipatory saccades. Group comparisons of the behavioral data were conducted using $T$-test for independent samples in SPSS 18.0 (SPSS Inc., Chicago, Illinois). All tests were two-tailed, with a value of $p<0.05$ to determine statistical significance. During fMRI-scanning, the eyeposition trace was observed to confirm in all participants that they performed the task as instructed. The experimenter noted any lapses on the part of the participant, as well as excessive eye blinks. We had no indication that any of the participants did not understand the tasks, nor did we have any evidence that any of the participants did not perform the task while in the scanner.

The functional MRI data were preprocessed and analysed using Statistical Parametric Mapping 5 (SPM, Wellcome Trust Centre for Neuroimaging, University College London, UK, http:// www.fil.ion.ucl.ac.uk/spm). To correct for differences in image acquisition time between slices, slice timing correction was conducted. The movement artifacts in the time-series of images were removed using a least squares approach and a six-parameter (rigid body) spatial transformation. Maximum head movement never exceeded $3 \mathrm{~mm}$ and no scans had to be removed due to excessive head motion. The images were realigned to spatially match the first image. The structural image was realigned to a mean image computed from the functional series. All images were then normalized to the Montreal Neurological Institute (MNI152) space. The realigned and normalized functional series were resampled to $2 \times 2 \times 2 \mathrm{~mm}$ resolution and spatially smoothed with a Gaussian kernel of $8 \mathrm{~mm}$ Full-Width at Half-Maximum (FWHM).

For the statistical analysis, the convolution of a canonical hemodynamic response function (HRF) with square temporal 
onset profiles (boxcars), representing the onsets of the relevant experimental conditions (the stimulus onset events for pro-saccades, anti-saccades, and fixation), were used to define the regressors, after removing the first three volumes. Except for anticipatory saccades, all trials (correct and incorrect) entered into the analysis. Motion parameters estimated during preprocessing of the functional images were included as additional regressors in the GLM model. Instructions and feedback were modeled as separate events of no interest. Single subject $T$ contrast maps were derived by $t$-statistics utilizing the canonical haemodynamic response function (HRF). In a second level random-effects analysis, between group differences in neural activation associated with the relevant contrasts were assessed using a one-way ANOVA. Within this ANOVA two-sample $t$-tests were computed to analyse effects between young healthy subjects and healthy elderly, as well as between healthy elderly and MCI patients. Clusters of $k \geq 10$ contiguous voxels large enough to pass a cluster-wise threshold of $p<0.001$ were considered as significant. Active brain areas were labeled with anatomical loci and Brodmann areas by using the SPM5 extension Wake Forest University (WFU) pick-atlas (Maldjian et al., 2003). The WFU pick-atlas was also used to convert MNI- in Talairachcoordinates. To assess age related changes in brain activation, the regions of interest (ROI) based approach was employed. The analysis was done on subject-specific parameter estimates extracted from the peak voxel within each region of interest using the MarsBAR toolbox in SPM5 (Marseille Boîte $\grave{A}$ Région d'Intérêt; http://marsbar.sourceforge.net/). This strategy allows for an anatomically focused analysis of the role of specific brain areas in saccade and anti-saccade task performance (Connolly et al., 2002; Curtis et al., 2004). ROIs were chosen on the basis of the relevant literature and our a priori hypothesis that activation of these regions would be modulated by the age and cognitive status of the participants. The regions associated with pro-saccadic and anti-saccadic eye movements have been well-described in the literature (Connolly et al., 2002; Matsuda et al., 2004; Brown et al., 2006; Parton et al., 2007; Hutton, 2008). Previous studies showed that fronto-parietal network is crucial for the planning and execution of saccadic eye movements (Rivaud et al., 1994; Matsuda et al., 2004; Grosbras et al., 2005). There is some inconsistency; however, whether frontal eye fields (FEF) or intraparietal sulcus (IPS) is more active during anti-saccades compared with prosaccades (Connolly et al., 2002; Cornelissen et al., 2002; Curtis et al., 2004; Brown et al., 2006; Ettinger et al., 2008). Thus, the sets of regions of interest were defined for prosaccades and antisaccades that included frontal and parietal regions as well as supplementary eye fields. Therefore, we used a literature-derived anatomical approach to investigate the effect of normal and pathological ageing on saccade-rated activations within frontal, parietal and supplementary eye fields. The ROIs with $5 \mathrm{~mm}$ radius ( $10 \mathrm{~mm}$ diameter) are displayed in Table 2 and labeled in Figure 1. First, we defined an anatomical mask (structural ROIs) for each subject based on his or her high-resolution structural scan. Then, the magnitude of activation within each ROI was calculated for each subject as the percent signal change for the relevant conditions over the voxels within the regions of interest (Poldrack, 2007).
Table 2 | Anatomical locations of regions of interest in the left and right hemispheres.

\begin{tabular}{lccc}
\hline Cortical region (ROI) & \multicolumn{3}{c}{ Talairach coordinates (in mm) } \\
\cline { 2 - 4 } & $\boldsymbol{x}$ & $\boldsymbol{y}$ & $\boldsymbol{z}$ \\
\hline Frontal eye fields & -32 & 16 & 48 \\
& 20 & 8 & 48 \\
\hline Parietal eye fields & 38 & -47 & 48 \\
& -43 & -50 & 52 \\
\hline Supplementary eye fields* & 17 & -17 & 56 \\
\hline
\end{tabular}

${ }^{*}$ Activation in supplementary eye fields is pooled over left and right hemispheres.

\section{RESULTS}

\section{BEHAVIORAL DATA}

The analysis of the behavioral performance measured outside of the scanner revealed that the groups did not differ in accuracy on the pro-saccade task (Table 3 ). In contrast, healthy elderly persons and aMCI-patients exhibited more direction errors while performing anti-saccades. However, the aMCI group did not differ significantly with respect to the proportion of omissions (i.e., proportion of trials where they executed no saccade) compared to the age-matched controls (Table 3 ). Compared to young persons, healthy elderly persons executed significantly fewer correct antisaccades and needed significantly more time to perform the task correctly. Furthermore, healthy elderly persons were significantly slower in pro-saccade task in comparison with young persons. Patients with aMCI executed significantly fewer correct antisaccades compared to elderly healthy persons. The reaction times, however, did not differ significantly in either of tasks between both groups.

\section{FUNCTIONAL IMAGING DATA}

Separate analyses for each group showed increased activation of distributed frontal and parietal regions in both pro-saccades and anti-saccades (Table 4). These areas are known to be involved in the execution of saccadic eye movements.

Region of interest analysis revealed that there are no significant differences in the neural activation between groups while performing pro-saccade task (pro-saccades $>$ fixation of healthy elderly compared to pro-saccades $>$ fixation of aMCI; Table 4). There are, however, significant changes in the activation associated with anti-saccade task with respect to age as well as with the aMCI diagnosis. While healthy elderly showed significantly less activation bilaterally in parietal regions compared to young persons, patients with aMCI exhibited significantly decreased activation bilateral in frontal regions (FEF) in comparison to healthy elderly participants.

\section{DISCUSSION}

The present study aimed to explore the effects of normal and pathological ageing on inhibitory processes underlying the control of reactive saccade execution. In particular, we investigated the behavioral and neural correlates of prepotent response 


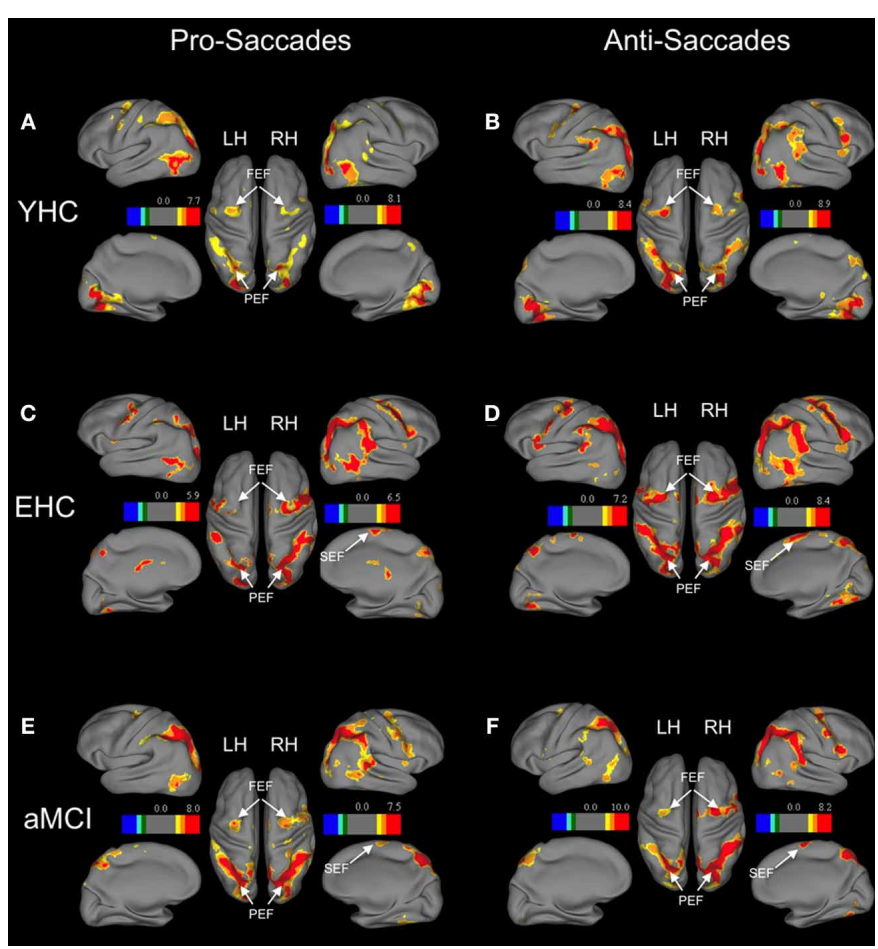

FIGURE 1 | Brain areas showing significant activation associated with pro-saccades and anti-saccades in all subject groups (contrasts: pro-saccades $>$ baseline, anti-saccades $>$ baseline). (Panels $A, C, E$ ) present the results for the pro-saccade condition, whereas (Panels $\mathbf{B}, \mathbf{D}, \mathbf{F}$ ) display the results for the anti-saccade condition. Abbreviations: YHC young healthy controls; $\mathrm{EHC}$, elderly healthy controls; a $\mathrm{MCl}$, patients with mild cognitive impairment; $\mathrm{LH}$, left hemisphere; $\mathrm{RH}$, right hemisphere; $F E F$, frontal eye fields; SEF, supplementary eye fields; PEF, parietal eye fields. Color insets present the $T$-values for the contrast saccade condition vs. baseline.

Table 3 | Performance measured outside of the scanner (proportion correct among executed saccades, proportion of omissions, reaction times in $\mathrm{ms}$ ) of young persons, healthy elderly and aMCl patients in pro-saccade and anti-saccade task.

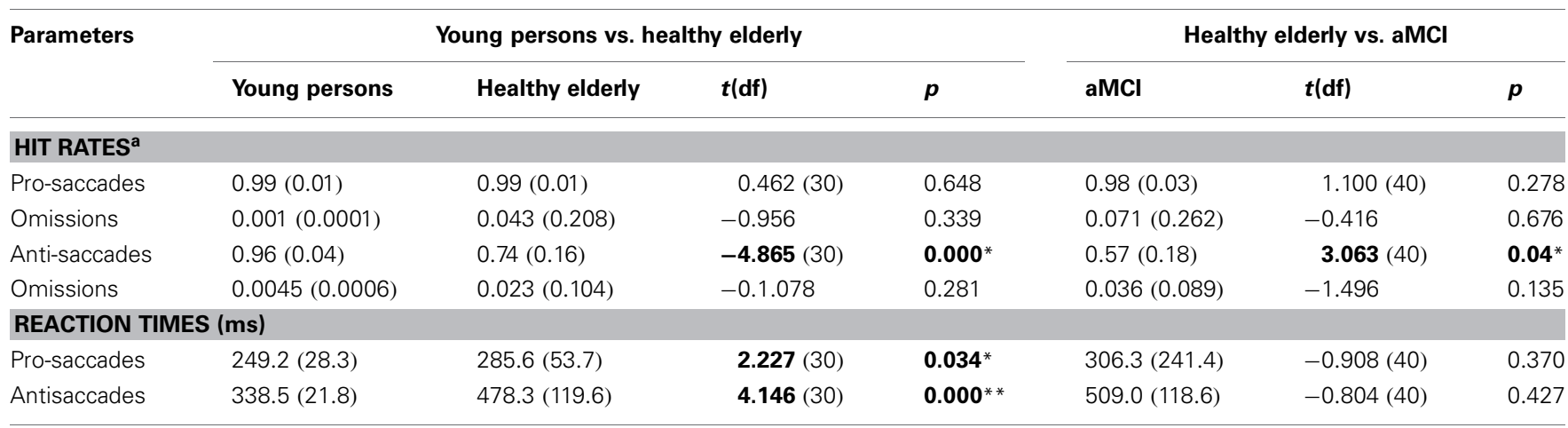

aMCl, amnestic mild cognitive impairment; n.s., not significant; denoted are mean values, standard deviations (in brackets), Z- and p-values. Levels of significance indicated by askerisks: ${ }^{*} p<0.05 ;{ }^{*} p<0.01$.

${ }^{a}$ Note that there were 4 possible target positions. Thus, performance by chance would correspond to a hit rate of $25 \%$.

Significant values $(p<0.05)$ are marked in bold font.

inhibition, assessed by the anti-saccade task, as postulated by Miyake et al. (2000) and Friedman and Miyake (2004). Our findings point to a significant impairment in the ability of aMCI patients to perform the antisaccade task. Furthermore, our findings indicate that this impaired execution of antisaccades is associated with significantly reduced BOLD signal in the frontal eye fields in aMCI patients. Our results are consistent with earlier studies (e.g., Amieva et al., 2004) on the effects of ageing and dementia on saccadic execution.

\section{SACCADIC AND ANTI-SACCADIC EYE MOVEMENTS IN NORMAL AGEING}

In agreement with studies on the decline of inhibitory processes with age (e.g., Hasher and Zacks, 1988; Nieuwenhuis et al., 2000; 
Table 4 | Results of regions of interest analysis in young persons, healthy elderly and aMCl patients (BOLD response as percent signal change within ROI across all trials).

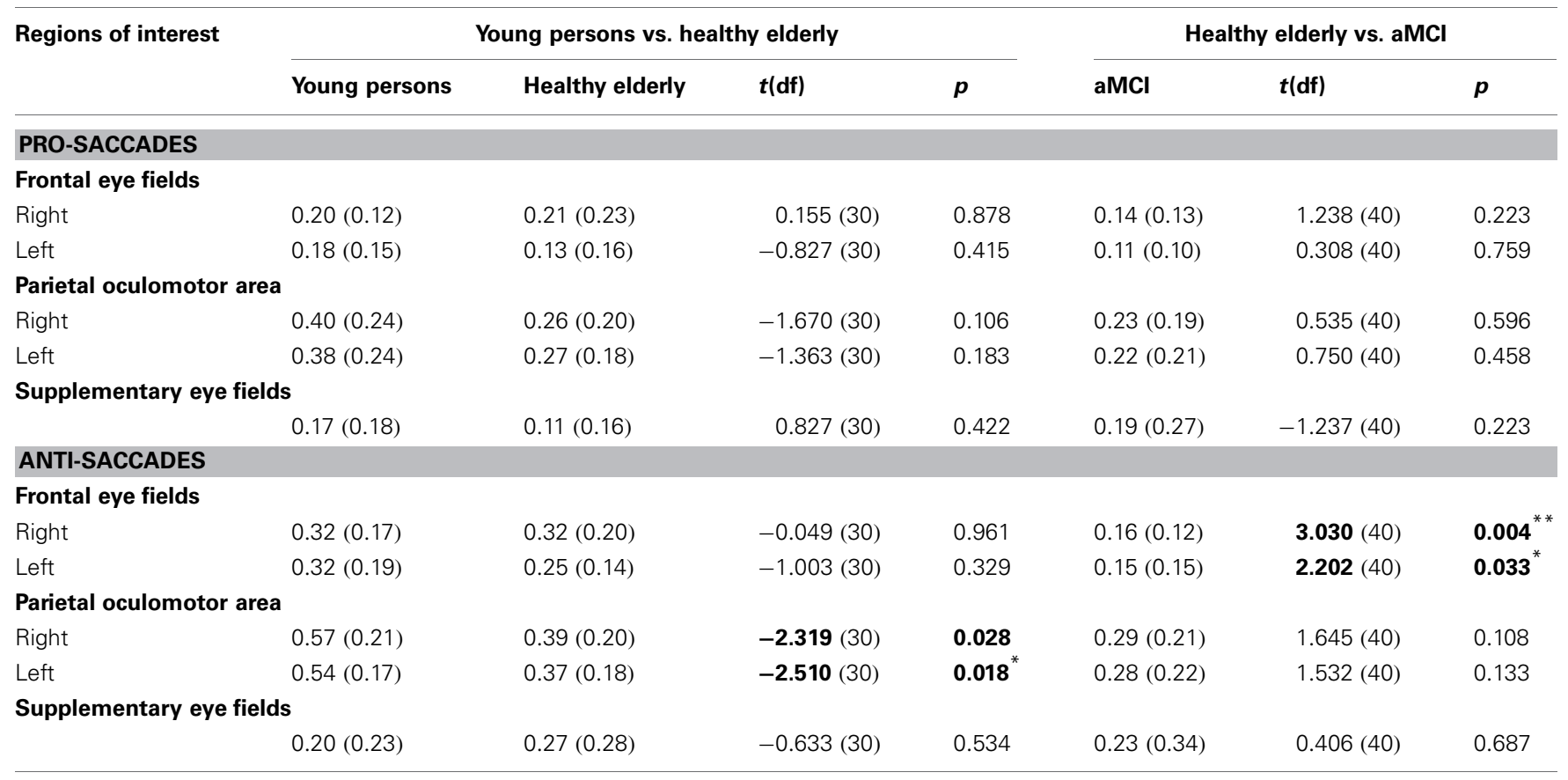

aMCl, amnestic mild cognitive impairment; denoted are mean values, standard deviations (in brackets), $t$ - and $p$-values, df: degrees of freedom. Levels of significance indicated by askerisks: ${ }^{*} p<0.05 ;{ }^{* *} p<0.01$.

Significant values $(p<0.05)$ are marked in bold font.

Sweeney et al., 2001; Raemaekers et al., 2006; Peltsch et al., 2011), our study demonstrates a reduced ability of elderly adults to voluntarily inhibit saccadic responses compared to young adults. Moreover, the onset latencies of pro-saccades and anti-saccades were significantly longer in healthy elderly adults compared to young adults (Table 3 ). The performance of elderly adults on the automatic saccadic initiation, however, showed no decline compared to the performance of young adults on the pro-saccade task. Such findings have been documented by previous research on pro-saccadic and anti-saccadic eye movements (Olincy et al., 1997; Butler et al., 1999; Klein and Foerster, 2001; Sweeney et al., 2001; Crawford et al., 2005; Peltsch et al., 2011). Moreover, some researchers demonstrated that the poor performance in the antisaccade task and longer saccadic latencies cannot only be found in elderly persons but also in children aged between 5 and 8 years (Munoz et al., 1998). Thus, these behavioral changes in performance may reflect different stages of normal development as well as degeneration in the nervous system (Munoz et al., 1998).

\section{SACCADIC AND ANTI-SACCADIC EYE MOVEMENTS IN PATHOLOGICAL AGEING}

The present study revealed impaired inhibitory functions in aMCI patients, as assessed by the anti-saccade task. Our results agree with those of previous studies that show altered inhibitory functions on Stroop task in aMCI patients (Traykov et al., 2007; Bélanger et al., 2010). Controversially, Zhang et al. (2007) failed to find significant differences in performance on Stroop task in MCI. These contrasting findings point to the heterogeneity underlying MCI (Nordlund, 2005). Furthermore, deterioration of controlled inhibition processes and preserved ability to execute pro-saccades has been widely reported in patients with $\mathrm{AD}$ (e.g., Currie et al., 1991; Amieva et al., 2002; Crawford et al., 2005; Mosimann et al., 2005; Collette et al., 2009). Moreover, there is evidence in the literature that persons diagnosed with $\mathrm{AD}$ demonstrate different performance patterns in oculomotor tasks compared to patients with Parkinson's disease with dementia, dementia with Lewy bodies (Mosimann et al., 2005), frontotemporal lobar degeneration, corticobasal syndrome and progressive supranuclear palsy (Garbutt et al., 2008). Thus, the anti-saccade task can also be used to distinguish between different types of dementia and other forms of degenerative disorders. Given the fact that persons with aMCI are likely to develop AD (Petersen and Jack, 2009), our findings illustrate that assessment of the prepotent inhibitory functions in aMCI might be sensitive to early manifestations of $\mathrm{AD}$.

\section{NEURAL CORRELATES OF INHIBITORY PROCESSES IN NORMAL AGEING}

The analysis of neural activation associated with saccadic inhibition showed that all groups found significant activations in regions that are thought to underlie the execution of pro- and anti-saccades (Pierrot-Deseilligny et al., 1991; Matsuda et al., 2004; Ford et al., 2005; Parton et al., 2007). A ROI analysis of the anti-saccade task revealed that healthy elderly adults show significantly less activation bilaterally in the inferior parietal lobe compared to young adults. This change in neural activation was 
accompanied by a significant reduction in performance accuracy and longer onset latencies. However, neither parietal nor frontal regions showed significant changes in activation during the prosaccade task, even though elderly healthy adults needed significantly more time to perform as accurately as young adults. In contrast, Raemaekers et al. (2006) reported no significant effect of age on the neural activation with respect to saccadic inhibition but lower activation in older adults compared to young and middle-aged adults who executed pro-saccades. Nevertheless, no significant difference in performance on either task was found between groups (Raemaekers et al., 2006). Nelles et al. (2009) showed an age-dependent increase in activation in a pro-saccade task in bilateral parietal eye fields, the right frontal eye field, as well as in the right extrastriate cortex. However, the previous study did not report any findings on the task performance of the individuals. The discrepancy between studies of Raemaekers et al. (2006); Nelles et al. (2009) and our study may be explained with increased interindividual variability in performance in cognitive tasks, which has been widely reported in elderly adults (for a review: Hedden and Gabrieli, 2004; Bishop et al., 2010). Also, the number of participants in both studies is lower compared to our study: Raemaekers et al. (2006) investigated three groups with a total number of 36 persons whereas the subject population in the study of Nelles et al. (2009) contained in total 22 persons. Furthermore, the present findings are consistent with those of previous studies illustrating effects of normal ageing on performance in oculomotor tasks (e.g., Fletcher and Sharpe, 1986; Mulligan et al., 1996). Hence, our findings extend these results and show an association between decreased activation in the parietal lobe in elderly adults and a decline in response inhibition.

Previous fMRI studies stressed the role of parietal areas in the execution of anti-saccades (Kimmig et al., 2001; Curtis and D'Esposito, 2003; Brown et al., 2006). More recently, Sharpe et al. (2011) showed that impaired suppression of reflexive saccades and generation of anti-saccades could be attributed to a partial disconnection of the parietal lobe from frontal lobe ocular motor areas. Given that reduction in fractional anisotropy of frontal and parietal white matter increases with age (Abe et al., 2002; Grieve et al., 2007), a decrease in parietal activation in elderly adults may result as a change in functional connectivity between these regions as seen in our study. Moreover, decreased activation in parietal regions together with reduced performance was observed in elderly adults in a Stroop task (Milham et al., 2002). In another study, right prefrontal and parietal regions were more activated in elderly adults compared to young persons during "successful inhibition" assessed with the Stroop interference paradigm (Nielson et al., 2002). This activation patterns can be explained by theoretical models of ageing (Cabeza et al., 2004; Grady et al., 2008; Reuter-Lorenz and Park, 2010) postulating that increases (or decreases) in activation refer to neural resources that are engaged (or disengaged) in healthy elderly to cope with cognitive challenges. Consistent with those models, neuroimaging findings indicate that in cases of limited cognitive decline with age, an over-activation is observed in regions important for the cognitive tasks in question (Cabeza et al., 2004). However, when cognitive impairment is more advanced, both decreased neural activity and poor performance on behavioral tasks have been reported in elderly adults (Persson and Nyberg, 2006). Hence, the failure to differentially activate the parietal regions may indicate neural inefficiency in elderly adults as seen in our study, accompanied by a decline in the ability to perform the demanding anti-saccade task requiring saccadic inhibition. Owing to the limitations with respect to the signalto-noise of the in-scanner eye-tracking data, we only used the eye-movement data online to confirm that the participants performed the task. The non-linear changes in the eye-tracking signal and the low signal-to noise level, however, made a detailed offline analysis unfeasible. Thus, we were not able to conduct a detailed off-line analysis of the eye-movement data collected in the scanner.

\section{NEURAL CORRELATES OF INHIBITORY PROCESSES IN PATHOLOGICAL AGEING}

Another important focus of our study was directed to the effects of pathological ageing on saccadic inhibition. To our knowledge, this is the first study that investigated anti-saccades and their neural correlates in aMCI. We found that while there is no significant difference in activation related to the pro-saccade task between aMCI patients and elderly adults, aMCI patients show significantly reduced activation in FEF bilaterally during the execution of anti-saccades. Given the fact that aMCI patients demonstrate a significant decline in the ability to correctly execute anti-saccades as compared to healthy elderly, these findings provide new evidence for an association between neural and cognitive deficits in pathological ageing. The reduced activation we observed in the aMCI group compared to the age-matched controls cannot be explained by a larger proportion of omissions in the antisaccade task. At least for the measurements made outside of the scanner the two groups did not differ with respect to the proportion of omissions during either anti- or pro-saccade tasks (Table 3).

Similar to the fMRI findings on the control of pro-saccades and anti-saccades in aMCI, there is only a limited number of studies that examine the effect of pathological ageing on neural activation associated with oculomotor tasks. Only one other study has investigated brain activation patterns during visually guided saccade paradigm in persons diagnosed with probable $\mathrm{AD}$ compared to healthy volunteers. Thulborn et al. (2000) observed left-dominant parietal and prefrontal cortical activation in most patients with probable $\mathrm{AD}$ while executing pro-saccades. An explanation for this contrasting result could be the difference between clinically diagnosed probable $\mathrm{AD}$ and $\mathrm{MCI}$, which both are pathologically heterogeneous disorders that vary in presentation, onset, or clinical course (Schneider et al., 2009). Furthermore, the inability of persons with $\mathrm{AD}$ to perform anti-saccades has been attributed to frontal lobe degeneration (Fletcher and Sharpe, 1986). Also the level of the performance on the Stroop task in patients with $\mathrm{AD}$ depends on the functional integrity of the prefrontal cortices (Yun et al., 2011). In a study investigating white matter tracts in MCI, authors showed that tract degeneration in frontal and cingulate regions as well as cortical thinning in caudal middle frontal region are associated with impairment 
in executive functions (Grambaite et al., 2011). Hence, the decrease in neural activation in FEF during anti-saccade task in patients with aMCI may be an analogous effect to the one seen in patients with AD. Furthermore, findings from our previous study demonstrated no significant differences in gray matter (VBM) between healthy elderly and persons with MCI (Alichniewicz et al., 2012). Moreover, the fact that the BOLD response is normal for pro-saccades in MCI speaks against an anatomical change in the gray matter in these patients and emphasizes the pathological functional disabilities. Therefore, our findings illustrate that the decline in functions for response inhibition accompanied by disrupted frontal activation in aMCI might be sensitive to early manifestations of AD.

\section{SHORTCOMING OF CURRENT STUDY AND MOTIVATION FOR FUTURE RESEARCH}

Our study characterizes the extent of oculomotor system impairment and altered neural activation in brain areas associated with response inhibition in normal and pathological ageing. The present study relies on eye-tracking performance outside the scanner for comparing the groups. Owing to problems related to signal-to-noise in the eye-tracking data collected in the scanner, we could only verify task compliance "on-line" and were unable to conduct any detailed off-line analysis of the eye-movement data that could have been used to determine error-related processing, perform a parametric analysis related to saccadic reaction times, or determine the role of correction saccades in the pattern of activation found in the aMCI group. Such interesting and relevant analyses are therefore left to future studies.

Moreover, randomized pro- and anti-saccade trial sequences would avoid habituation or adaptation effects associated with block presentation of the different saccade types. However, within each block saccade direction and amplitude were randomized to minimize such adaptation effects. The results of many previous studies suggest that a number of different processes underlie a cognitive decline in $\mathrm{AD}$ and $\mathrm{MCI}$ (for a review: Stephan et al., 2012a). Thus, we believe that determining the factors that account for behavioral and functional changes reported in this study requires further research.

Furthermore, studies investigating functional connectivity suggest that spontaneous fluctuations in the BOLD signal may contribute to the variability in evoked signals and performance levels (Fox et al., 2006; Fox and Raichle, 2007). Resting-state functional connectivity between the FEF and prefrontal as well as intraparietal cortex exhibits a remarkable similarity across macaque and humans (Hutchison et al., 2012). Also, the extent

\section{REFERENCES}

Abe, O., Aoki, S., Hayashi, N., Yamada, H., Kunimatsu, A., Mori, H., et al. (2002). Normal aging in the central nervous system: quantitative MR diffusion-tensor analysis. Neurobiol. Aging 23, 433-441. doi: $\quad 10.1016 /$ S0197-4580(01) 00318-9
Alichniewicz, K. K., Brunner, F., Klünemann, H. H., and Greenlee, M. W. (2012). Structural and functional neural correlates of visuospatial information processing in normal aging and amnestic mild cognitive impairment. Neurobiol. Aging 33, 2782-2797. doi: 10.1016/ j.neurobiolaging.2012.02.010

of task-related reduction in neural activity in default mode regions was shown to be less pronounced in older than in young adults (Lustig et al., 2003; Grady et al., 2006), especially with increasing cognitive task demands (Persson et al., 2007). Since we used a general linear model analysis that is not as sensitive to temporal change in activation and deactivation patterns in dementia as are exploratory data analysis techniques, such as independent component analysis (ICA) (Rombouts et al., 2009), we cannot eliminate the possibility that we may not have been able to detect additional unknown group differences in our neuroimaging data. Hence, important implications regarding the role of the age reductions in the ability to suppress default mode activity in elderly adults during demanding inhibition tasks such as anti-saccade task need to be investigated.

\section{CONCLUSIONS}

The aim of this study was to further our understanding of cognitive and neural changes in normal and pathological ageing with respect to inhibitory functions, in particular inhibition of prepotent responses measured in anti-saccade tasks. The present study confirms and extends existing results showing that healthy ageing leads to reduced response inhibition and decreased neural activation in the parietal lobe. Furthermore, our study provides new insights in the neural changes associated with the execution of anti-saccades that occur in pathological ageing. Our functional MRI data revealed that patients with aMCI show reduced activation in frontal eye fields together with reduced ability to execute anti-saccades. A reduced ability to voluntarily suppress an automatic response in favor of performing an alternative behavior is considered to be one of the crucial executive functions required in everyday life (Munoz and Everling, 2004). An analysis of the error-related activations on erroneous anti-saccade trials would have been informative. Thus, future work should address whether alteration of neural activation associated with oculomotor performance found in aMCI can help to detect persons at risk of developing Alzheimer's disease.

\section{ACKNOWLEDGMENTS}

This research was funded in part by Deutsche Forschun gsgemeinschaft (GR 988). Author K. K. Alichniewicz gratefully acknowledges The Bavarian Academic Center for Central, Eastern and Southeastern Europe (BAYHOST) for a PhD scholarship. We thank the participants for their enthusiastic support. The authors would like to thank the reviewers for their extensive and immensely helpful comments on this manuscript thoroughout the review process.

American Psychiatric Association. (1994). Diagnostic and Statistical Manual of Mental Disorders (DSM). 4th Edn. APA Publishing.

Amieva, H., Lafont, S., Auriacombe, S., Carret, N. L., Dartigues, J.-F., Orgogozo, J.-M., et al. (2002). Inhibitory breakdown and dementia of the Alzheimer type: a
General Phenomenon? J. Clin. Exp. Neuropsychol. 24, 503-516. doi: 10.1076/jcen.24.4.503.1034

Amieva, H., Phillips, L. H., Della Sala, S., and Henry, J. D. (2004). Inhibitory functioning in Alzheimer's disease. Brain 127, 949-964. doi: 10.1093/brain/ awh045 
Anderson, S., Parbery-Clark, A., White-Schwoch, T., and Kraus, N. (2012). Aging affects neural precision of speech encoding. J. Neurosci. 32, 14156-14164. doi: 10.1523/JNEUROSCI.2176-12.2012

Artero, S., Petersen, R., Touchon, J., and Ritchie, K. (2006). Revised Criteria for mild cognitive impairment: validation within a longitudinal population study. Dement. Geriatr. Cogn. Disord. 22, 465-470. doi: 10.1159/ 000096287

Bélanger, S., and Belleville, S. (2009). Semantic inhibition impairment in mild cognitive impairment: a distinctive feature of upcoming cognitive decline? Neuropsychology 23, 592-606. doi: 10.1037/ a0016152

Bélanger, S., Belleville, S., and Gauthier, S. (2010). Inhibition impairments in Alzheimer's disease, mild cognitive impairment and healthy aging: effect of congruency proportion in a Stroop task. Neuropsychologia 48, 581-590. doi: 10.1016/ j.neuropsychologia.2009.10.021

Belleville, S., Rouleau, N., and Van der Linden, M. (2006). Use of the Hayling task to measure inhibition of prepotent responses in normal aging and Alzheimer's disease. Brain Cogn. 62, 113-119. doi: 10.1016/j.bandc.2006.04.006

Bishop, N. A., Lu, T., and Yankner, B. A. (2010). Neural mechanisms of ageing and cognitive decline. Nature 464, 529-535. doi: 10.1038/ nature 08983

Boxer, A. L., Garbutt, S., Rankin, K. P., Hellmuth, J., Neuhaus, J., Miller, B. L., et al. (2006). Medial versus lateral frontal lobe contributions to voluntary saccade control as revealed by the study of patients with frontal lobe degeneration. J. Neurosci. 26, 6354-6363. doi: $\quad 10.1523 /$ JNEUROSCI. 0549-06.2006

Braver, T. S., and Barch, D. M. (2002). A theory of cognitive control, aging cognition, and neuromodulation. Neurosci. Biobehav. Rev. 26, 809-817. doi: 10.1016/S0149-7634(02)00067-2

Brown, M. R. G., Goltz, H. C., Vilis, T., Ford, K. A., and Everling, S. (2006). Inhibition and generation of saccades: rapid event-related fMRI of prosaccades, antisaccades, and nogo trials. Neuroimage 33, 644-659. doi: $\quad 10.1016 /$ j.neuroimage. 2006.07.002

Butler, K., Zacks, R., and Henderson, J. (1999). Suppression of reflexive saccades in younger and older adults: age comparisons on an antisaccade task. Mem. Cognit. 27, 584-591. doi: 10.3758/ BF03211552

Cabeza, R., Daselaar, S. M., Dolcos, F., Prince, S. E., Budde, M. and Nyberg, L. (2004). Taskindependent and task-specific age effects on brain activity during working memory, visual attention and episodic retrieval. Cereb. Cortex 14, 364-375. doi: 10.1093/cercor/ bhg133

Chertkow, H., Massoud, F., Nasreddine, Z., Belleville, S., Joanette, Y., Bocti, C., et al. (2008). Diagnosis and treatment of dementia: 3. Mild cognitive impairment and cognitive impairment without dementia. CMAJ 178, 1273-1285.

Connolly, J. D., Goodale, M. A., Menon, R. S., and Munoz, D. P. (2002). Human fMRI evidence for the neural correlates of preparatory set. Nat. Neurosci. 5, 1345-1352. doi: 10.1038/nn969

Collette, F., Schmidt, C., Scherrer, C., Adam, S., and Salmon, E. (2009). Specificity of inhibitory deficits in normal aging and Alzheimer's disease. Neurobiol. Aging 30, 875-889. doi: 10.1016/j.neurobiolaging.2007. 09.007

Cornelissen, F. W., Kimmig, H., Schira, M., Rutschmann, R. M., Maguire, R. P., Broerse, A., et al. (2002). Event-related fMRI responses in the human frontal eye fields in a randomized pro- and antisaccade task. Exp. Brain Res. 145, 270-274. doi: 10.1007/s00221002-1136-3

Crawford, T. J., Higham, S., Renvoize, T., Patel, J., Dale, M., Suriya, A. and Tetley, S. (2005). Inhibitory control of saccadic eye movements and cognitive impairment in Alzheimer's disease. Biol. Psychiatry 57, 1052-1060. doi: $\quad$ 10.1016/j.biopsych.2005. 01.017

Crutcher, M. D., Calhoun-Haney, R., Manzanares, C. M., Lah, J. J., Levey, A. I., and Zola, S. M. (2009). Eye tracking during a visual paired comparison task as a predictor of early dementia. Am. J. Alzheimers Dis. Other Demen. 24 258-266. doi: $10.1177 / 153331750$ 9332093

Currie, J., Ramsden, B., McArthur, C. and Maruff, P. (1991). Validation of a clinical antisaccadic eye movement test in the assessment of dementia. Arch. Neurol. 48, 644-648. doi: 10.1001/archneur.1991.00530180102024

Curtis, C. E., and D'Esposito, M. (2003). Success and failure suppressing reflexive behavior. J. Cogn.
Neurosci. 15, 409-418. doi: 10.1162/ 089892903321593126

Curtis, C. E., Rao, V. Y., and D'Esposito, M. (2004). Maintenance of spatial and motor codes during oculomotor delayed response tasks. J. Neurosci. 24, 3944-3952. doi 10.1523/JNEUROSCI.5640-03.2004

Ettinger, U., ffytche, D. H., Kumari, V., Kathmann, N., Reuter, B., Zelaya, F., et al. (2008). Decomposing the neural correlates of antisaccade eye movements using event-related fMRI. Cereb. Cortex 18, 1148-1159. doi: 10.1093/cercor/bhm147

Fisher, L. M., Freed, D. M., and Corkin, S. (1990). Stroop ColorWord Test performance in patients with Alzheimer's disease. J. Clin. Exp. Neuropsychol. 12, 745-758. doi: 10.1080/01688639008401016

Fletcher, W. A., and Sharpe, J. A. (1986). Saccadic eye movement dysfunction in Alzheimer's disease. Ann. Neurol. 20, 464-471. doi: 10.1002/ana.410200405

Ford, K. A., Goltz, H. C., Brown, M. R. G., and Everling, S. (2005). Neural processes associated with antisaccade task performance investigated with event-related fMRI J. Neurophysiol. 94, 429-440. doi 10.1152/jn.00471.2004

Fox, M. D., and Raichle, M. E. (2007) Spontaneous fluctuations in brain activity observed with functional magnetic resonance imaging. Nat. Rev. Neurosci. 8, 700-711. doi: 10.1038/nrn2201

Fox, M. D., Snyder, A. Z., Zacks, J. M., and Raichle, M. E. (2006). Coherent spontaneous activity accounts for trial-to-trial variability in human evoked brain responses. Nat. Neurosci. 9, 23-25. doi: 10.1038/nn1616

Fox, N. C., Warrington, E. K., Seiffer, A. L., Agnew, S. K., and Rossor, M. N. (1998). Presymptomatic cognitive deficits in individuals at risk of familial Alzheimer's disease. A longitudinal prospective study. Brain 121, 1631-1639. doi: 10.1093/brain/121.9.1631

Friedman, N. P., Miyake, A., Young, S. E., DeFries, J. C., Corley, R. P., and Hewitt, J. K. (2008). Individual differences in executive functions are almost entirely genetic in origin. J. Exp. Psychol. Gen. 137, 201-225. doi: 10.1037/0096-3445.137.2.201

Friedman, N. P., and Miyake, A. (2004). The relations among inhibition and interference control functions: a latent-variable analysis. J. Exp. Psychol. Gen. 133, 101-135. doi: 10.1037/0096-3445.133.1.101

Garbutt, S., Matlin, A., Hellmuth, J., Schenk, A. K., Johnson, J.
K., Rosen, H., et al.(2008). Oculomotor function in frontotemporal lobar degeneration, related disorders and Alzheimer's disease. Brain 131, 1268-1281. doi: 10.1093/brain/awn047

Grady, C. L., Springer, M. V., Hongwanishkul, D., McIntosh, A. R., and Winocur, G. (2006). Agerelated changes in brain activity across the adult lifespan. J. Cogn. Neurosci. 18, 227-241. doi: 10.1162/ 089892906775783705

Grady, C. L., Yu, H., and Alain, C. (2008). Age-related differences in brain activity underlying working memory for spatial and nonspatial auditory information. Cereb. Cortex 18, 189-199. doi: 10.1093/cercor/ bhm045

Grambaite, R., Selnes, P., Reinvang, I., Aarsland, D., Hessen, E., Gjerstad, L., et al. (2011). Executive dysfunction in mild cognitive impairment is associated with changes in frontal and cingulate white matter tracts. J. Alzheimers Dis. 27, 453-462.

Greenwood, P. M. (2000). The frontal aging hypothesis evaluated. J. Int Neuropsychol. Soc. 6, 705-726. doi: $10.1017 / \mathrm{S} 1355617700666092$

Grieve, S. M., Williams, L. M., Paul, R. H., Clark, C. R., and Gordon, E. (2007). Cognitive aging, executive function, and fractional anisotropy: a diffusion tensor MR imaging study. Am. J. Neuroradiol. 28, 226-235.

Grosbras, M.-H., Laird, A. R., and Paus, T. (2005). Cortical regions involved in eye movements, shifts of attention, and gaze perception. Hum. Brain Mapp. 25, 140-154. doi: 10.1002/hbm. 20145

Hallett, P. (1978). Primary and secondary saccades to goals defined by instructions. Vision Res. 18, 1279-1296. doi: 10.1016/0042-6989(78)90218-3

Hasher, L., and Zacks, R. T. (1988). "Working memory, comprehension, and aging: a review and a new view," in The Psychology of Learning and Motivation, Vol. 22, ed G. H. Bower (New York, NY: Academic Press), 193-225. doi: 10.1016/S0079-7421 (08)60041-9

Hedden, T., and Gabrieli, J. D. E. (2004). Insights into the ageing mind: a view from cognitive neuroscience. Nat. Rev. Neurosci. 5, 87-96. doi: $10.1038 / \mathrm{nrn} 1323$

Heilbronner, U., and Münte, T. F. (2013). Rapid event-related near-infrared spectroscopy detects age-related qualitative changes in the neural correlates of response inhibition. 
Neuroimage $\quad 65, \quad 408-415$. doi: 10.1016/j.neuroimage.2012.09.066

Hunderfund, A. L., Roberts, R. O., Slusser, T. C., Leibson, C. L., Geda, Y. E., Ivnik, R. J., et al. (2006). Mortality in amnestic mild cognitive impairment. Neurology 67, 1764-1768. doi: 10.1212/ 01.wnl.0000244430.39969.5f

Hutchison, R. M., Gallivan, J. P., Culham, J. C., Gati, J. S., Menon, R. S., and Everling, S. (2012). Functional connectivity of the frontal eye fields in humans and macaque monkeys investigated with resting-state fMRI. J. Neurophysiol. 107, 2463-2474. doi: 10.1152/jn.00891.2011

Hutton, S. B. (2008). Cognitive control of saccadic eye movements. Brain Cogn. 68, 327-340. doi: 10.1016/j.bandc.2008.08.021

Iachini, T., Iavarone, A., Senese, V. P., Ruotolo, F., and Ruggiero, G. (2009). Visuospatial memory in healthy elderly, AD and MCI: a review. Curr. Aging Sci. 2, 43-59.

Johnson, D. K., Storandt, M., Morris, J. C., and Galvin, J. E. (2009). Longitudinal study of the transition from healthy aging to Alzheimer Disease. Arch. Neurol. 66, 1254-1259. doi: 10.1001/archneurol.2009.158

Kaufman, L. D., Pratt, J., Levine, B., and Black, S. E. (2010). Antisaccades: a probe into the dorsolateral prefrontal cortex in Alzheimer's disease. A critical review. J. Alzheimers Dis. 19, 781-793. doi: 10.3233/JAD2010-1275

Kaufman, L. D., Pratt, J., Levine, B., and Black, S. E. (2012). Executive deficits detected in mild Alzheimer's disease using the antisaccade task. Brain Behav. 2, 15-21. doi: 10.1002/brb3.28

Kimmig, H., Greenlee, M. W., Gondan, M., Schira, M., Kassubek, J., and Mergner, T. (2001). Relationship between saccadic eye movements and cortical activity as measured by fMRI: quantitative and qualitative aspects. Exp. Brain Res. 141, 184-194. doi: 10.1007/ s002210100844

Klein, C., and Foerster, F. (2001). Development of prosaccade and antisaccade task performance in participants aged 6 to 26 years. Psychophysiology 38, 179-189. doi: 10.1111/1469-8986.3820179

Kramer, J. H., Nelson, A., Johnson, J. K., Yaffe, K., Glenn, S., Rosen, H. J., et al. (2006). Multiple cognitive deficits in amnestic mild cognitive impairment. Dement. Geriatr. Cogn. Disord. 22, 306-311. doi: $10.1159 / 000095303$
Lagun, D., Manzanares, C., Zola, S. M., Buffalo, E. A., and Agichtein, E. (2011). Detecting cognitive impairment by eye movement analysis using automatic classification algorithms. J. Neurosci. Methods 201, 196-203. doi: 10.1016/j.jneumeth.2011.06.027

Langley, L. K., and Madden, D. J. (2000). Functional neuroimaging of memory: implications for cognitive aging. Microsc. Res. Tech. 51, 75-84.

Li, C., Zheng, J., Wang, J., Gui, L., and Li, C. (2009). An fMRI stroop task study of prefrontal cortical function in normal aging, mild cognitive impairment, and Alzheimers disease. Curr. Alzheimer Res. 6, 525-530. doi: 10.2174/156720509790147142

Logan, G. D., (ed.). (1994). On the Bility to Inhibit Thought and Action: a User's Guide to the Stop Signal Paradigm. Inhibitory Processes in Attention, Memory and Language. San Diego, CA: Academic Press.

Lustig, C., Snyder, A. Z., Bhakta, M., O’Brien, K. C., McAvoy, M., Raichle, M. E., et al. (2003). Functional deactivations: change with age and dementia of the Alzheimer type. Proc. Natl. Acad. Sci. U.S.A. 100, 14504-14509. doi: 10.1073/pnas.2235925100

Maldjian, J. A., Laurienti, P. J., Kraft, R. A., and Burdette, J. H. (2003). An automated method for neuroanatomic and cytoarchitectonic atlas-based interrogation of fMRI data sets. Neuroimage 19, 1233-1239. doi: 10.1016/S1053-8119(03)00169-1

Matsuda, T., Matsuura, M., Ohkubo, T., Ohkubo, H., Matsushima, E., Inoue, K., et al. (2004). Functional MRI mapping of brain activation during visually guided saccades and antisaccades: cortical and subcortical networks. Psychiatry Res. 131, 147-155. doi: 10.1016/j. pscychresns.2003.12.007

McDowd, J. M. (1997). Inhibition in attention and aging. J. Gerontol. $B$ Psychol. Sci. Soc. Sci. 52, P265-P273. doi: 10.1093/geronb/ 52B.6.P265

Milham, M. P., Erickson, K. I., Banich, M. T., Kramer, A. F., Webb, A., Wszalek, T., et al. (2002). Attentional control in the aging brain: insights from an fMRI Study of the Stroop Task. Brain Cogn. 49, 277-296. doi: 10.1006/brcg.2001.1501

Mirsky, J. B., Heuer, H. W., Jafari, A., Kramer, J. H., Schenk, A. K., Viskontas, I. V., et al. (2011). Anti-saccade performance predicts executive function and brain structure in normal elders. Cogn. Behav. Neurol. 24, 50-58. doi 10.1097/WNN.0b013e318223f6c6

Miyake, A., Friedman, N. P., Emerson, M. J., Witzki, A. H., Howerter, A., and Wager, T. D. (2000). The unity and diversity of executive functions and their contributions to complex "frontal lobe" tasks: a latent variable analysis. Cogn. Psychol. 41, 49-100. doi: 10.1006/cogp. 1999.0734

Moscovitch, M., and Winocur, G. (1992). "The neuropsychology of memory and aging," in The Handbook of Aging and Cognition, eds F. I. M. Craik and T. A. Salthouse (Hillsdale, NJ: Lawrence Erlbaum Associates), 315-372.

Mosimann, U. P., Muri, R. M., Burn, D. J., Felblinger, J., O’Brien, J. T., and McKeith, I. G. (2005). Saccadic eye movement changes in Parkinson's disease dementia and dementia with Lewy bodies. Brain 128, 1267-1276. doi: 10.1093/brain/ awh484

Mosimann, U. P., Müri, R. M., Burn, D. J., Felblinger, J., O’Brien, J. T., and McKeith, I. G. (2005). Saccadic eye movement changes in Parkinson's disease dementia and dementia with Lewy bodies. Brain 128, 1267-1276. doi: 10.1093/brain/awh484

Mulligan, R., Mackinnon, A., Jorm, A. F., Giannakopoulos, P., and Michel, J. P. (1996). A comparison of alternative methods of screening for dementia in clinical settings. Arch. Neurol. 53, 532-536. doi: 10.1001/ archneur.1996.00550060074019

Munoz, D. P., Broughton, J. R., Goldring, J. E., and Armstrong, I. T. (1998). Age-related performance of human subjects on saccadic eye movement tasks. Exp. Brain Res. 121, 391-400. doi: 10.1007/s002210050473

Munoz, D. P., and Everling, S. (2004). Look away: the anti-saccade task and the voluntary control of eye movement. Nat. Rev. Neurosci. 5, 218-228. doi: 10.1038/nrn1345

Nelles, G., de Greiff, A., Pscherer, A., and Esser, J. (2009). Agerelated differences of saccade induced cortical activation. Neurosci. Lett. 458, 15-18. doi: 10.1016/j.neulet.2009.04.026

Nielson, K. A., Langenecker, S. A., and Garavan, H. (2002). Differences in the functional neuroanatomy of inhibitory control across the adult life span. Psychol. Aging 17, 56-71. doi: 10.1037/0882-7974.17.1.56

Nieuwenhuis, S., Ridderinkhof, K. R., de Jong, R., Kok, A., and van der Molen, M. W. (2000). Inhibitory inefficiency and failures of intention activation: age-related decline in the control of saccadic eye movements. Psychol. Aging 15, 635-647. doi: 10.1037/0882-7974. 15.4 .635

Nordlund, A. (2005). The Goteborg MCI study: mild cognitive impairment is a heterogeneous condition. J. Neurol. Neurosurg. Psychiatry 76, 1485-1490. doi: 10.1136/jnnp.2004.050385

Olincy, A., Ross, R. G., Youngd, D. A., and Freedman, R. (1997). Age diminishes performance on an antisaccade eye movement task. Neurobiol. Aging 18, 483-489. doi: 10.1016/S0197-4580(97)00109-7

Park, D. C., and Reuter-Lorenz, P. (2009). The adaptive brain: aging and neurocognitive scaffolding. Annu. Rev. Psychol. 60, 173-196. doi: 10.1146/ annurev.psych.59.103006.093656

Parton, A., Nachev, P., Hodgson, T. L., Mort, D., Thomas, D., Ordidge, R. et al. (2007). Role of the human supplementary eye field in the control of saccadic eye movements. Neuropsychologia 45, 997-1008. doi: 10.1016/ j.neuropsychologia.2006.09.007

Peltsch, A., Hemraj, A., Garcia, A. and Munoz, D. P. (2011). Agerelated trends in saccade characteristics among the elderly. Neurobiol. Aging 32, 669-679. doi: 10.1016/ j.neurobiolaging.2009.04.001

Persson, J., Lustig, C., Nelson, J. K., and Reuter-Lorenz, P. A. (2007). Age differences in deactivation: a link to cognitive control? J. Cogn. Neurosci. 19, 1021-1032. doi: 10.1162/jocn. 2007.19.6.1021

Persson, J., and Nyberg, L. (2006). Altered brain activity in healthy seniors: what does it mean? Prog. Brain Res. 157, 45-56. doi: 10.1016/S0079-6123(06)57004-9

Petersen, R. (2004). Mild cognitive impairment as a diagnostic entity. J. Intern. Med. 256, 183-194. doi: 10.1111/j.1365-2796.2004.01388.x

Petersen, R. C. (2003). Mild cognitive impairment clinical trials. Nat. Rev. Drug Discov. 2, 646-653. doi: 10.1038/nrd1155

Petersen, R. C. (2007). The current status of mild cognitive impairment[mdash]what do we tell our patients? Nat. Clin. Pract. Neurol. 3, 60-61. doi: 10.1038/ ncpneuro0402

Petersen, R. C., and Jack, C. R. (2009). Imaging and biomarkers in early Alzheimer's disease and mild cognitive impairment. Clin. Pharmacol. Ther. 86, 438-441. doi: 10.1038/clpt. 2009.166 
Pierrot-Deseilligny, C., Rivaud, S., Gaymard, B., and Agid, Y. (1991). Cortical control of reflexive visually-guided saccades. Brain 114 , 1472-1485. doi: 10.1093/brain/114. 3.1473

Poldrack, R. A. (2007). Region of interest analysis for fMRI. Soc. Cogn. Affect. Neurosci. 2, 67-70. doi: 10.1093/scan/nsm006

Raczkowski, D., Kalat, J. W., and Nebes, R. (1974). Reliability and validity of some handedness questionnaire items. Neuropsychologia 12, 43-47. doi: 10.1016/0028-3932(74) 90025-6

Raemaekers, M., Vink, M., Heuvel, M. P. V. D., Kahn, R. S., and Ramsey, N. F. (2006). Effects of aging on BOLD fMRI during prosaccades and antisaccades. J. Cogn. Neurosci. 18, 594-603. doi: 10.1162/jocn.2006.18.4.594

Rapp, P. R., and Amaral, D. G. (1992). Individual differences in the cognitive and neurobiological consequences of normal aging. Trends Neurosci. 15, 340-345. doi: 10.1016/01662236(92)90051-9

Reuter-Lorenz, P. A., and Park, D. C. (2010). Human neuroscience and the aging mind: a new look at old problems. J. Gerontol. B Psychol. Sci. Soc. Sci. 65, 405-415. doi: 10.1093/ geronb/gbq035

Rivaud, S., Muri, R., Gaymard, B., Vermesch, A., and PierrotDeseilligny, C. (1994). Eye movement disorders after frontal eye field lesions in humans. Exp. Brain Res. 102, 110-120. doi: 10.1007/BF00232443
Rombouts, S. A. R. B., Damoiseaux, J. S., Goekoop, R., Barkhof, F., Scheltens, P., Smith, S. M., and Beckmann, C. F. (2009). Modelfree group analysis shows altered BOLD FMRI networks in dementia. Hum. Brain Mapp. 30, 256-266. doi: 10.1002/hbm.20505

Rozzini, L., Chilovi, B. V., Conti, M., Bertoletti, E., Delrio, I., Trabucchi, M., and Padovani, A. (2007). Conversion of amnestic mild cognitive impairment to dementia of Alzheimer type is independent to memory deterioration. Int. J. Geriatr. Psychiatry 22, 1217-1222. doi: 10.1002/gps.1816

Sachdev, P. S., Lipnicki, D. M., Crawford, J., Reppermund, S., Kochan, N. A., Trollor, J. N., et al. (2012). Risk profiles of subtypes of mild cognitive impairment: the Sydney memory and ageing study. J. Am. Geriatr. Soc. 60, 24-33. doi: 10.1111/j.1532-5415.2011.03774.x

Schneider, J. A., Arvanitakis, Z., Leurgans, S. E., and Bennett, D. A. (2009). The neuropathology of probable Alzheimer disease and mild cognitive impairment. Ann. Neurol. 66, 200-208. doi: 10.1002/ana.21706

Sharpe, J. A., Cheng, P., and Eizenman, M. (2011). Antisaccade generation is impaired after parietal lobe lesions. Ann. N.Y. Acad. Sci. 1233, 194-199. doi: 10.1111/j.1749-6632.2011.06178.x

Stephan, B. C. M., Hunter, S., Harris D., Llewellyn, D. J., Siervo, M., Matthews, F. E., et al. (2012a). The neuropathological profile of mild cognitive impairment
(MCI): a systematic review. Mol. Psychiatry 17, 1056-1076. doi 10.1038/mp.2011.147

Stephan, B. C. M., Matthews, F. E., Hunter, S., Savva, G. M., Bond, J., McKeith, I. G., et al. (2012b) Neuropathological profile of mild cognitive impairment from a population perspective. Alzheimer Dis. Assoc. Disord. 26, 205-212. doi 10.1097/WAD.0b013e31822fc24d

Stroop, J. R. (1935). Studies of interference in serial verbal reactions. J. Exp. Psychol. 18, 643-662. doi 10.1037/h0054651

Sweeney, J. A., Rosano, C., Berman, R. A., and Luna, B. (2001) Inhibitory control of attention declines more than working memory during normal aging. Neurobiol. Aging 22, 39-47. doi 10.1016/S0197-4580(00)00175-5

Thulborn, K. R., Martin, C., and Voyvodic, J. T. (2000). Functional MR imaging using a visually guided saccade paradigm for comparing activation patterns in patients with probable Alzheimer's disease and in cognitively able elderly volunteers. Am. J. Neuroradiol. 21, 524-531.

Traykov, L., Raoux, N., Latour, F., Gallo, L., Hanon, O., Baudic, S., et al. (2007). Executive functions deficit in mild cognitive impairment. Cogn. Behav. Neurol. 20, 219-224. doi: 10.1097/ WNN.0b013e31815e6254

Yun, J. Y., Lee, D. Y., Seo, E. H., Choo I. H., Park, S. Y., Kim, S. G., et al. (2011). Neural correlates of stroop performance in Alzheimer's disease: a FDG-PET study. Dement. Geriatr.
Cogn. Disord. Extra 1, 190-201. doi: 10.1159/000329517

Zhang, Y., Han, B., Verhaeghen, P., and Nilsson, L.-G. (2007) Executive functioning in older adults with mild cognitive impairment: MCI has effects on planning, but not on inhibition. Aging Neuropsychol. Cogn. 14, 557-570. doi: $10.1080 / 13825580600788118$

Conflict of Interest Statement: The authors declare that the research was conducted in the absence of any commercial or financial relationships that could be construed as a potential conflict of interest.

Received: 03 January 2013; accepted: 04 July 2013; published online: 24 July 2013. Citation: Alichniewicz KK, Brunner F, Klünemann HH and Greenlee MW (2013) Neural correlates of saccadic inhibition in healthy elderly and patients with amnestic mild cognitive impairment. Front. Psychol. 4:467. doi: 10.3389/fpsyg.2013.00467

This article was submitted to Frontiers in Perception Science, a specialty of Frontiers in Psychology.

Copyright (C) 2013 Alichniewicz, Brunner, Klünemann and Greenlee. This is an open-access article distributed under the terms of the Creative Commons Attribution License, which permits use, distribution and reproduction in other forums, provided the original authors and source are credited and subject to any copyright notices concerning any third-party graphics etc. 